\title{
Using neoteric solvents in oil shale studies*
}

\author{
M. Koel ${ }^{1, \dagger}$, S. Ljovin ${ }^{1}$, K. Hollis ${ }^{2}$, and J. Rubin ${ }^{2}$ \\ ${ }^{1}$ Institute of Chemistry, Akadeemia tee 15, Tallinn 12618, Estonia; ${ }^{2}$ Los Alamos \\ National Laboratory, P.O. Box 1663, Los Alamos, NM 87545, USA
}

\begin{abstract}
The liquefaction, gasification, and other chemical modifications of oil shale are challenging goals of chemistry and chemical engineering. The use of new solvent systems, such as supercritical fluids and ionic liquids, represents new avenues in the search of environmentally benign technologies. Supercritical fluid extraction (SFE) with carbon dioxide is particularly effective for the isolation of substances of medium molecular weight and relatively low polarity. At elevated temperatures it is possible to unite the breaking chemical bonds in the kerogen organic matter and convert the former into oil with extraction using supercritical fluids. Quantitative and qualitative information obtained at different temperatures during SFE is providing some insight into the speciation of hydrocarbons in geological samples. Ionic liquids were studied as potential solvents for kerogen extraction. However, these chemical processes are favored at elevated temperatures up to the thermal degradation temperature of kerogen, $\approx 400{ }^{\circ} \mathrm{C}$. There were observed significant differences in the chemical composition of extracted oil and from the oil from the classical semicoking process of oil shale. An additional application would be a combination of the two methods- the use of supercritical carbon dioxide to recover nonvolatile organic compounds from room-temperature ionic liquid without using organic solvents.
\end{abstract}

\section{INTRODUCTION}

Prof. Kenneth R. Seddon from The Queen's University of Belfast has introduced the term "neoteric solvents" [1], referring to ionic liquids and supercritical fluids that have remarkable new properties, and that offer a potential for industrial application. These neoteric solvents are characterized by physical and chemical properties that can be finely tuned for a range of applications by varying the chemical constituents in the case of ionic liquids and by varying physical parameters in the case of supercritical fluids. Both of these solvent systems are being evaluated in oil shale studies. Supercritical fluid solvents are already in use for industrially important processes, but ionic liquids have only recently been applied in this area.

The world's known reserves of oil shale are vast, being many times greater than the proven remaining resources of crude oil and natural gas combined [2]. These resources could therefore play an important role in energy supply for the future, and conversion of solid fuels (e.g., coal, oil shale, biomass) to chemicals feedstock and cleaner-burning liquid or gaseous fuels is becoming more desirable. The utilization of oil shale containing sufficient amount of organic matter, is feasible and, under certain conditions, economically worthwhile.

The organic part of oil shale, kerogen, is a cross-linked macromolecular system. The essence of an oil shale liquefaction process is the structural degradation of and/or the addition of hydrogen to a kerogen material, with heteroatom removal being an important consideration. The oldest and most

\footnotetext{
*Lecture presented at the International Symposium on Green Chemistry, Delhi, India, 10-13 January 2001. Other presentations are published in this issue, pp. 77-203.

$\dagger$ Corresponding author.
} 
widely spread method is pyrolysis, but this needs in every form high-energy input to thermally break down the kerogen matrix. There is considerable interest in alternative methods to convert kerogen into soluble products, preferably methods that operate at near-ambient temperatures.

\section{SOLVENT EXTRACTION}

The extraction of an analyte from sample consists of several steps, including solvation of the analyte by extraction solvent, desorption from the matrix surface, and, finally, transportation of the analyte into the bulk extraction liquid. The solvent can play different roles in the extraction process, either solubilization and extraction of smaller, unbound molecules, which are present in oil shale matrix, and/or by attacking the kerogen structure.

The first case represents classical extraction, and it would be expected that the conversion (extraction yield) would depend predominantly on the solvent ability to solubilize at the extraction conditions (solubility). There would be little, if any, effect of the chemical structure of the extracting fluid on the conversion of unbound molecules into the flow of extracting fluid from the matrix.

Most oil shales (among them also Estonian) have quite inert kerogen matrix and give very little extractables with different solvents at normal conditions. There are two types of oil shale in the Baltic Basin: 1) the lower Ordovician Dictyonema shale from the Maardu deposit, Estonia. The inorganic part of this shale is primarily clay (76\%) with a small proportion of carbonate (3\%). The organic content is approximately $20 \%$, and not in industrial use; 2) The Middle Ordovician Kukersite oil shale from Estonian deposit. The inorganic part is minerologically complex, composed primarily of carbonates $(41 \%)$ and clay (26\%). The organic content is approximately $36 \%$. This is the resource of Estonian oil shale industry.

The results for each type of oil shale show that the extraction yield depends differently on the nature of the solvent (Table 1). In oil shale, kerogen is tightly mixed with mineral matrix, however, in most cases demineralization do not affect very much kerogen solubility. It is true for both Estonian oil shale where the yield was not increased after demineralization by acids.

In the second case, when the solvent attacks the kerogen and the chemical modification or the degradation of kerogen occurs, the solvent structure would be of considerable importance. These chemical processes take place in most cases at elevated temperatures but below thermal degradation temperature of oil shale $\left(<400^{\circ} \mathrm{C}\right)$. Solvents having different physical and chemical properties can break bonds based on electron donor-electron acceptor interactions and hydrogen bonding. Water, alcohols, or aliphatic amines could be such solvents to improve the conversion of kerogen matrix into smaller mol-

Table 1 Extraction yield from Estonian oil shales using organic solvents. The ground oil shale $(\sim 3 \mathrm{~g})$ is extracted with $10 \mathrm{ml}$ of solvent at room temperature (left overnight $16 \mathrm{~h}$, shaken for $1 \mathrm{~h}$, and sonicated in an ultrasonic water bath for $1 \mathrm{~h}$ ). The yield was estimated gravimetrically: $6 \mathrm{ml}$ of solvent extract was pipetted into a tared beaker and allowed to evaporate at room temperature.

\begin{tabular}{lcc}
\hline \multirow{2}{*}{ Solvent } & \multicolumn{2}{c}{ Yield (wt \%) } \\
\cline { 2 - 3 } & Dictyonema & Kukersite \\
\hline Methanol & 0.52 & 0.07 \\
Acetonitrile & 0.03 & 0.33 \\
Acetone & 0.10 & 0.09 \\
Methylene chloride & 0.10 & 0.07 \\
Tetrahydrofuran & 0.40 & 0.40 \\
Toluene & 0.06 & 0.01 \\
Hexane & 0.01 & 0.01 \\
\hline
\end{tabular}


ecules. It must be pointed out, however, that solvents can behave differently for different types of oil shale because of the difference in the composition and structure of each shale.

\section{Supercritical fluid extraction of Estonian oil shale}

Recent concerns about the hazardous nature of many commonly used solvents, environmental danger of waste solvent disposal, and the emission of hazardous solvents into the atmosphere during sample concentration further support the development for better and more environmental friendly extraction techniques for analytical laboratories.

Soxhlet extraction is the standard method for oil shale, but it has a number of drawbacks. Not only is the extraction very time-consuming, but also the large volumes of toxic organic solvents that are required must later be evaporated to concentrate the extract. The limitations of conventional methods have fuelled interest in the study of supercritical fluid extraction (SFE) as an alternative to organic solvent methods. Supercritical fluid has been used for petrochemical applications [3,4] as useful alternatives to techniques, which employ conventional liquid solvents. The previous remarks made concerning solvent extraction applies well to SFE [5] - the supercritical fluid extracts smaller molecules that are present in oil shale but not bound to the kerogen matrix, while a supercritical solvent (or with modifier) can be made to interact with the kerogen structure.

Carbon dioxide $\left(\mathrm{CO}_{2}\right)$ is most commonly used as the supercritical fluid primarily because of its easily accessible critical parameters $\left(31.1^{\circ} \mathrm{C}\right.$ and $\left.7.38 \mathrm{MPa}\right)$. Further, it is noncombustible, nontoxic, and inexpensive. The principal drawback of $\mathrm{CO}_{2}$ as supercritical fluid, however, is its low polarity, meaning that it cannot efficiently extract organic compounds from the kerogen without the addition of polar organic modifiers, such as methanol.

Estonian oil shale Kukersite, having predominantly the carbonate mineral matrix, gave very similar yields of Soxhlet extraction with chloroform and carbon dioxide SFE extracts (on the level of $\sim 1 \mathrm{mg} / \mathrm{g}$ for $1 \mathrm{~h}$ of extraction time) [6,7]. That means that during Soxhlet extraction and SFE with carbon dioxide even with modifiers and at higher temperatures most of the kerogen matrix remains untouched, and only part of the organics that is not included in the structure of kerogen can be extracted from the oil shale matrix. Longer extraction time and/or increased temperature both increased the yield substantially. However, even $2 \mathrm{~h}$ extraction with $\mathrm{CO}_{2}$ at $150{ }^{\circ} \mathrm{C}$ was not exhaustive (on the level of $\sim 3 \mathrm{mg} / \mathrm{g}$ ). During the extraction the main kerogen matrix remains untouched. Mainly, $n$-alkanes were extracted by pure carbon dioxide, whereas modifying the fluid with methanol led to the intensification of the extraction of more polar compounds such as isoprenoid alkanes, polyclic hydrocarbons (steranes and triterpanes), and as a result, to an increase in the total yield of extract. Compounds that are usually extracted from Kukersite in two steps separately with chloroform and, after treatment with hydrochloric acid, with a benzene/methanol mixture, are co-extracted by the carbon dioxide modified with methanol.

The substantial increase in extraction yield with increased extraction temperature can be explained either by an increased solubility of extractable compounds, or the compounds are released due to thermally induced structural changes in the matrix. Above $200{ }^{\circ} \mathrm{C}$ it becomes clear that partial destruction of insoluble kerogen of Kukersite took place, but pyrolysis products are not dominant in extracts. Moreover, there is an essential difference between the semicoking shale oil and high-temperature SFE extracts. Semicoking of oil shale always results in the coformation of $n$-alkenes with $n$-alkanes. High-temperature SFE with $\mathrm{CO}_{2}$, on the other hand, resulted no n-alkenes in the extract.

Another environmentally favorable solvent is water, and its use at subcritical conditions also allows extraction of the organics not incorporated into the kerogen matrix, similar to nonpolar organic solvents. Indeed, the extraction yield from Kukersite at $200{ }^{\circ} \mathrm{C}$ with water was quite similar to that obtained from methanol-modified carbon dioxide, and resulted in a comparable composition.

At supercritical conditions, water can be used for degradation of kerogen, and this can be used to produce oil form shale. These kinds of experiments, conducted in autoclaves, were performed previ-

(C) 2001 IUPAC, Pure and Applied Chemistry 73, 153-159 
ously to investigate the decomposition of Kukersite using different solvents (water, water- $\mathrm{NaOH}$, and benzene) [8]. At $250{ }^{\circ} \mathrm{C}$ the oil yield were low (5-10\% of the total organic matter). The authors of the present work, using a flow-through reactor, confirmed the results. Increasing the temperature up to $300{ }^{\circ} \mathrm{C}$ yields oil up to $35 \%$ in aqueous medium and $58 \%$ in the benzene medium. The extracts were characterized by a high content of aliphatic compounds, especially by olefins with a double bond in the middle of the chain. The addition of the organic solvent to water ratio increased extraction yields in all cases. Using the binary system of benzene-water $(1: 1)$ and at the temperature of $350{ }^{\circ} \mathrm{C}$ resulted in an increased extraction up to $74 \%$. The extracts consist of high-molecular-weight oils containing a great deal of asphaltenes [9], and the yield is comparable to Fischer assay results. The study also investigated the addition of water to the $\mathrm{CO}_{2}$ at a 1:5 ratio. Results showed a marked effect on the conversion of shale at $340{ }^{\circ} \mathrm{C}$ - the yields of extract were $27 \%$ larger than with pure $\mathrm{CO}_{2}$ and $63 \%$ than extraction with pure water [10]. Overall recovery was reported to levels as high as $94 \%$ of the kerogen. It should be noted that all of these processes take place at lower temperatures compared to the typical retorting method.

In these experiments, one must keep in mind that thermolysis of the modificator near the critical point in the presence of minerals can lead to the formation of additional product. Also, during the extraction in the supercritical state using modificators to carbon dioxide having a hydrogen-donor capability like alcohols should be considered as hydrogenation rather than "true" supercritical gas extraction [11].

\section{MOLTEN SALTS TREATMENT OF OIL SHALE.}

One possible way to attack the kerogen is to use molten salts as decomposition media having chemical effects in addition to its role as a thermal agent. The physical properties of ionic salt melts lie between those of molten metals and of water. Their good heat transfer properties, low vapor pressures, and good thermal stability are important factors in their performance as reaction and solvent media.

There are few samples of the study of oil shale processing in molten salt media. As a result, gaseous and liquid products are starting to evolve at lower temperatures than in the absence of molten salt. Miron [12] studied oil shale and ammonium nitrate reactions above the melting temperature of last $\sim 170{ }^{\circ} \mathrm{C}$. Another melted bath at relatively low temperatures is a mixture of $\mathrm{Na}, \mathrm{Li}$, and $\mathrm{K}$ hydroxides at $200{ }^{\circ} \mathrm{C}$. The results show that processing of oil shale at $200-225^{\circ} \mathrm{C}$ in the presence of oxygen and water gives an organic product consisting of hydrocarbon fraction in the gasoline-diesel fuel range and an acid aqueous fraction. Very little further refining appears to be necessary for these products [13]. In studies of liquefaction of bituminous coal, the processing with molten chlorides $\mathrm{SnCl}_{2} / \mathrm{KCl}$ takes place at higher temperatures (up to $400{ }^{\circ} \mathrm{C}$ ) [14]. Chlorides act as catalysts, and in applications they have been used for hydrocracking.

Most molten salts are liquid only at high temperatures and offer little advantage over the more commonly used aqueous or organic media. There have been recent developments, which have produced molten salts at room temperature. These room-temperature ionic liquids open new possibilities to perform organic reactions and extraction techniques, and very low vapor pressure makes them environmentally favorable. The first ionic liquids were made on the basis of aluminium chloride, which is a well-known catalyst for several reactions, and this way it was natural to suggest "It is also of interest as a solvent for the liquefaction of coal" [15]. There have been only limited studies performed with the use of ionic liquid for oil shale treatment.

The very first study was on Green River oil shale, which was degraded using a eutectic of ethylpyridinium bromide and aluminium chloride, a liquid at ambient temperature [16]. This solvent has interesting Lewis acid-base properties and was acting as a base in this experiment. A conversion of $58 \%$ of organic carbon present reported at temperature $320{ }^{\circ} \mathrm{C}$. Results of the extract indicate the process involved was not driven by pyrolysis. 
The most studied ionic liquids are imidazolium-based salts where cations have different length of alkyl chains and anions are varied. The imidazolium chloroaluminate room-temperature ionic liquids provide a medium for Friedel-Crafts alkylation and acylations acting both as a solvent and as a catalyst [17]. Complex of studies on treatment of oil shale with ionic liquids was done in University of Sussex where Y. Patell [18] and L. M. Dutta [19] were looking for dissolution of kerogens. They demonstrated that kerogen dissolves in acidic ionic liquid, 1-ethyl-3-methylimidazoliumchloridealuminum(III)chloride, where mole fraction of $\mathrm{AlCl}_{3}$ is 0.65 . Dissolution of up to $95 \%$ of the kerogens occurs. Also, that treatment under microwave irradiation improved the dissolution.

Ionic liquids containing chloroaluminate are moisture sensitive, which makes their handling complicated, but now there are moisture-stable ionic liquids available (one example could be 1-butyl-3-methylimidazolium hexafluorophosphate). They can be used as solvents for catalysts for reactions [20].

Our experiments with 1-butyl-3-methylimidazolium hexafluorophosphate $\left\{[\mathrm{BMIm}] \cdot \mathrm{PF}_{6}\right\}$ and 1-ethyl-3-methylimidazoliumchloride-aluminum(III)chloride $\left\{[\mathrm{BMIm}] \mathrm{Cl} \cdot \mathrm{AlCl}_{3}\right\}$ showed some interesting results. We find that $[\mathrm{BMIm}] \cdot \mathrm{PF}_{6}$ is significantly miscible with organic solvents having a static dielectric constant higher than about 7. However, this salt is immiscible with water. The $[\mathrm{BMIm}] \mathrm{Cl} \cdot \mathrm{AlCl}_{3}$ salt showed considerably more reactivity toward these same solvents, with the acidic $\left(\mathrm{AlCl}_{3}\right.$ rich) liquid stable only with acetonitrile and methylene chloride.

The hexaflourophosphate ionic liquid appears to be a poor solvent for either oil shale at room temperature ( $24 \mathrm{~h}$ experiment). The yield of soluble products was only $0.07 \%$ for the Dictyonema shale and $0.02 \%$ for the Kukersite shale. These values are close to the yield obtained from a methylene chloride extraction. However, the room-temperature extraction yields using the chloroaluminate salts are much higher, but they are still on the level of best organic solvents $(0.28 \%$ for Dictyonema shale with acidic ionic liquid and $0.26 \%$ for Kukersite with basic ionic liquid). According to these percentages, there is no expectation of chemical activity of ionic liquids yet.

It is generally known that the thermal degradation of oil shale kerogen begins at $200{ }^{\circ} \mathrm{C}$. To eliminate the influence of pyrolysis during the contact with ionic liquids the extraction temperature was kept below this degradation temperature $\left(175^{\circ} \mathrm{C}\right)$.

From these experiments it is seen that even for the higher extraction temperatures, the hexafluorophosphate ionic liquid possesses a low level of chemical activity as evidenced by the fact that the yield of solubilized kerogen was more or less independent of extraction temperature. This trend was seen for both types of shale. For the acidic chloroaluminate ionic liquid, the extraction yield generally increased with extraction temperature, suggesting that this ionic liquid does not function as a thermal agent but has catalytic activity and is solubilizing kerogen.

For Kukersite, increasing extraction temperature increases yield of soluble product in the case of acidic IL substantially (up to $4 \%$ from total mass of shale taken). For basic ionic liquid there was only a small increase in the recovery of kerogen at $175^{\circ} \mathrm{C}$. The extraction of Kukersite with acidic IL is a good example both of weight recovery and GC data to show the increase yield of extract with temperature increase.

For Dictyonema, the increase in yield of soluble products was estimated in the case of basic IL (up to $1.7 \%$ from total mass of shale taken); acidic IL gives slight increase, but the yield remains lower than $0.5 \%$.

A qualitative comparison of the extracted oil shale shows a general trend of recovery of the organic material to the $\mathrm{C}_{10}$ range and has a maximum peak height in the $\mathrm{C}_{15}$ retention time. The GC analysis confirms the absence of significant low-molecular-weight material, less than $\mathrm{C}_{5}$, which would result from the volatilization during the gravimetric process.

Ionic liquid being itself a Lewis acid or solvent for acid could be applied for acid-catalyzed oil shale conversion for producing liquid and gaseous products at lower temperatures than pyrolysis. When these acid catalyst systems can be readily regenerated, their use will be not limited. Ionic liquids could 
be used to overcome the difficulties in catalysis to find a means to bring hydrogen gas in proper molecular contact with the kerogen, especially if a solid catalyst is used.

Recovering nonvolatile organic compounds from room-temperature ionic liquid without using organic solvents has been limiting the use of these environmentally benign liquids in manufacturing. This is the meeting point with another environmentally benign solvent-supercritical carbon dioxideto carry out such separations. J. Brennecke et al. [21] demonstrated that $\mathrm{CO}_{2}$ and [BMIm] $\cdot \mathrm{PF}_{6}$ could be used together as extraction system. Supercritical $\mathrm{CO}_{2}$ dissolves in the liquid to facilitate extraction, but the ionic liquid does not dissolve in carbon dioxide, so pure product can be recovered. This was a very promising demonstration that can bring a breakthrough in the technology of extraction with ionic liquids.

\section{CONCLUSIONS}

Novel solvent systems as supercritical fluids and ionic liquids have shown very promising properties for green chemistry applications in oil shale processing. These processes must be the part of complex use of oil shale where the output contains valuable chemicals and energy from the organic part of oil shale and harmless mineral residue.

\section{ACKNOWLEDGMENTS}

Estonian Science Foundation is acknowledged for support of supercritical fluid studies, and Los Alamos National Laboratory for providing the opportunity to perform the ionic liquid studies.

\section{REFERENCES}

1. K. R. Seddon. Kinetics and Catalysis 37, 693-697 (1996).

2. P. L. Russell. Oil Shales of the World, Their Origin, Occurrence and Exploitation, Pergamon Press (1990).

3. D. F. Williams. Chem. Eng. Sci. 36(11), 1769-1788 (1981).

4. J. M. Levy. J. High Res. Chromatog. 17(4), 212-216 (1994).

5. J. R. Kershaw. Fuel 76(5), 453-454 (1997).

6. M. Koel and E. Bondar. Fuel 77(3), 211-213 (1998).

7. E. Bondar, M. Koel, M. Liiv. Fuel 77(3), 215-219 (1998).

8. L. Nappa, I. Klesment, N. Vink, K. Kailas (in Russian). Proc. Est. Acad. Chem. 31(1), 17-24 (1982).

9. H. Luik and I. Klesment (in Russian). Proc. Est. Acad. Chem. 34(1), 253-263 (1985).

10. H. Luik and I. Klesment (in Russian). Proc. Est. Acad. Chem. 37(4), 279-281 (1988).

11. J. Jezko, D. Gray, J. R. Kershaw. Fuel Proc. Tech. 5, 229-239 (1982).

12. Y. Miron. Thermochim. Acta 65, 213-237 (1983).

13. A. D. Hues, C. K. Rofer-DePoorter, R. N. Rogers. Proc. ACS Petro. Chem. Meeting (1984).

14. M. Nomura, T. Muratani, Y. Tajima, S. Murata. Fuel Proc. Tech. 43, 213-225 (1995).

15. R. L. Perry, K. J. Jones, W. D. Scott, Qing Liao, C. L. Hussey. J. Chem. Eng. Data 40(3), 615-619 (1995).

16. R. C. Bugle, K. Wilson, G. Olsen, L. G. Wade Jr., R. A. Osteryoung. Nature 274, 578-580 (1978).

17. J. A. Boon, J. A. Levisky, J. L. Plug, J. S. Wilkes. J. Org. Chem. 51(4), 480-483 (1986).

18. Y. Patell. The dissolution of kerogens, Thesis of M.Phil., Univ. of Sussex, (1993).

19. L. M. Dutta. The dissolution of Liassic kerogen and coal, Thesis of M.Phil., Univ. of Sussex (1994). 
20. M. J. Earle, P. B. McCormac, K. R. Seddon. Chem. Comm. 20, 2245-2246 (1998).

21. L. A. Blanchard, D. Hancu, E. J. Beckmann, J. Brennecke. Nature 399, $28-29$ (1999). 